\title{
Multiphysics Theoretical Evaluation of Thermal Stresses in Laser Machined Structural Alumina
}

\author{
Hitesh D. Vora • Narendra B. Dahotre
}

Accepted: 30 December 2014 / Published online: 17 January 2015

(C) Springer New York 2015

\begin{abstract}
Lasers are being explored as innovative machining tools to efficiently fabricate complex shapes and contours in hard and brittle structural ceramics. Although, the concentrated nature of laser beam is capable of providing suitable conditions for efficient machining of structural ceramics, it often generates steep temperature gradient that leads to generation of the detrimental thermal stresses. These thermal stresses are likely to be sufficient to nucleate the micro-cracks and subsequent crack propagation or growth can lead to failure. In light of this, a theoretical approach was employed in the present efforts to evaluate the thermal stresses during laser machining of structural alumina ceramic. A multistep multiphysics computational model was designed and developed to estimate thermal stresses during multidimensional laser machining of structural alumina. The environmental scanning electron microscopy (ESEM) observations were carried out to detect the micro-cracks generated due to the thermal stresses on the surface of laser machined alumina under various machining conditions.
\end{abstract}

Keywords Nd:YAG pulsed laser - Laser machining - Alumina - Computational model . Thermal stresses

\section{Abbreviations}

$\mathrm{Al}_{2} \mathrm{O}_{3} \quad$ Alumina or aluminum oxide

$\mathrm{ZrO}_{2} \quad$ Zirconia or zirconium oxide

$\mathrm{MgO} \quad$ Magnesia or magnesium oxide

$\mathrm{SiC} \quad$ Silicon carbide

$\mathrm{Si}_{3} \mathrm{~N}_{4} \quad$ Silicon nitride

\section{H. D. Vora}

Department of Mechanical Engineering Technology, Oklahoma State University,

Stillwater, OK 74078, USA

\section{N. B. Dahotre $(\bowtie)$}

Laboratory for Laser Aided Additive and Subtractive Manufacturing, Department of Materials Science and Engineering, University of North Texas, 1155 Union Circle \# 305310, Denton, TX 76203-5017, USA e-mail: Narendra.Dahotre@unt.edu

URL: http://mtse.unt.edu/Dahotre/ 
Nd:YAG Neodymium-doped yttrium aluminum garnet

$\rho \quad$ Density $\left(\mathrm{kg} / \mathrm{m}^{3}\right)$

$C_{p} \quad$ Specific heat at constant pressure (J/kg.K)

$K \quad$ Thermal conductivity (W/m.K)

$T \quad$ Temperature (K)

$t \quad$ Time (s)

$X \quad \mathrm{x}$-coordinate $(\mathrm{m})$

$Y \quad$ y-coordinate $(\mathrm{m})$

Z Z-coordinate (m)

$C_{p} 1 \quad$ Modified specific heat at constant pressure (J/kg.K)

$\delta_{m} \quad$ Normalization function around the melting temperature $\left(\mathrm{K}^{-1}\right)$

$\delta_{v} \quad$ Normalization function around the vaporization temperature $\left(\mathrm{K}^{-1}\right)$

$H^{\prime} \quad$ Smooth heaviside function

$L_{m} \quad$ Latent heat of melting $(\mathrm{J} / \mathrm{g})$

$T_{m} \quad$ Melting temperature (K)

$\Delta T \quad$ Half-width of the curve $(\mathrm{K})$

$L_{v} \quad$ Latent heat of evaporation $(\mathrm{J} / \mathrm{g})$

$T_{v} \quad$ Vaporization temperature $(\mathrm{K})$

$B \quad$ Fraction of a particular phase (solid, liquid or vapor)

$T_{x} \quad$ Transition temperature between two phases, solid-liquid or vapor-liquid (K)

$\varphi \quad$ Laser on/off function

$P_{g} \quad$ Average laser power density $\left(\mathrm{W} / \mathrm{m}^{2}\right)$

$H \quad$ Heat transfer coefficient $\left(\mathrm{W} / \mathrm{m}^{2} . \mathrm{K}\right)$

$T_{a} \quad$ Ambient temperature (K)

$T_{i} \quad$ Initial temperature $(\mathrm{K})$

$\varepsilon 1 \quad$ Emissivity

ol Stefan-Boltzmann constant $\left(\mathrm{W} / \mathrm{m}^{2} \cdot \mathrm{K}^{4}\right)$

$A \quad$ Absorptivity of laser beam

$t_{1} \quad$ Time just below melting temperature before solidification

$t_{2} \quad$ Time just below melting temperature during solidification

$f \quad$ Pulse rate or pulses per second

$P_{w} \quad$ Pulse width (s)

$D \quad$ Diameter of laser beam (m)

$E_{p} \quad$ Energy per pulse (J)

$E_{d} \quad$ Average laser energy density per pulse $\left(\mathrm{J} / \mathrm{m}^{2}\right)$

$E_{\text {eff }} \quad$ Effective laser energy density per pulse $\left(\mathrm{J} / \mathrm{m}^{2}\right)$

tg Time gap between two pulses (s)

$V \quad$ Scanning speed $(\mathrm{mm} / \mathrm{s})$

$x_{r} \quad$ Reference point to represents the center of the laser beam along x-axis (m)

$y_{r} \quad$ Reference point to represents the center of the laser beam along $\mathrm{y}$-axis (m)

$\phi \quad$ Standard deviation of the Gaussian laser beam (m)

$u \quad$ Velocity in the $\mathrm{x}$-direction $(\mathrm{m} / \mathrm{s})$

$v \quad$ Velocity in the y-direction $(\mathrm{m} / \mathrm{s})$

$w \quad$ Velocity in the z-direction $(\mathrm{m} / \mathrm{s})$

u2 Displacement in the $\mathrm{x}$-direction $(\mathrm{m} / \mathrm{s})$

$v 2 \quad$ Displacement in the y-direction $(\mathrm{m} / \mathrm{s})$

$w 2$ Displacement in the $\mathrm{z}$-direction $(\mathrm{m} / \mathrm{s})$ 


\begin{tabular}{|c|c|}
\hline E & Elastic modulus \\
\hline$\nu$ & Poisson’s ratio \\
\hline$\varepsilon$ & Total strain tensor \\
\hline$\sigma$ & Stress tensor \\
\hline$C$ & 4 th order elasticity tensor \\
\hline : & Double-dot tensor product (or double contraction) \\
\hline$s_{0}$ & Initial stress $(\mathrm{Pa})$ \\
\hline$\varepsilon_{0}$ & Initial strain \\
\hline$\varepsilon_{t h}$ & Thermal strain \\
\hline$\alpha$ & Thermal expansion coefficient $\left(\mathrm{K}^{-1}\right)$ \\
\hline$T_{r e f}$ & Reference temperature $(\mathrm{K})$ \\
\hline$p$ & Pressure $\left(\mathrm{N} / \mathrm{m}^{2}\right)$ \\
\hline$g$ & Gravitational constant $\left(\mathrm{m} / \mathrm{s}^{2}\right)$ \\
\hline$P_{r}$ & Recoil pressure $\left(\mathrm{N} / \mathrm{m}^{2}\right)$ \\
\hline$T_{s}$ & Instantaneous surface temperature $(\mathrm{K})$ \\
\hline$M_{v}$ & Mass of vapor molecule (kg/atm) \\
\hline$\gamma$ & Surface tension (N/m.K) \\
\hline$\mu$ & Dynamic viscosity (Pa.s) \\
\hline$R$ & Universal gas constant (J/mol.K) \\
\hline $\mathrm{SiO}_{2}$ & Silicon dioxide \\
\hline $\mathrm{Fe}_{2} \mathrm{O}_{3}$ & Iron oxide \\
\hline $\mathrm{R}_{2} \mathrm{O}$ & Base or fluxing oxides \\
\hline$D_{L}$ & Lateral distance between two laser pulses (mm) \\
\hline$O_{L}$ & Lateral overlap (\%) \\
\hline$D_{T}$ & Transverse distance between two laser tracks (mm) \\
\hline$O_{T}$ & Transverse overlap (\%) \\
\hline
\end{tabular}

\section{Introduction}

Laser machining techniques have appeared as a promising technology to efficiently and effectively machine hard and brittle structural ceramics (alumina, magnesia, zirconia, silicon carbide, and silicon nitride) into complex shapes and geometries [1-29]. On the other hand, during pulsed mode laser machining of structural ceramics (due to higher melting temperatures and lower thermal conductivity), the localized nature of heating (small laser beam and laser-material interaction zone) creates the larger temperature gradient due to sudden temperature rise and fall [4, 6, 8, 10-17] that in turn likely to induce the thermal stresses and subsequent crack nucleation in the small laser-material interaction zone and surrounding heat affected zone (HAZ) [30-33]. Thus, generation of thermal stresses poses a serious limitation for this innovative laser machining technology to effectively fabricate structural ceramics.

Previously, a considerable amount of experimental and computational work [20, 22-26, 29-45] was carried out to investigate the role of thermal stresses during laser machining of structural ceramics and its effects on the machining quality. In these studies, researchers proposed various methodologies and approaches to effectively machine ceramics, such as by active stressing techniques to delay fracture during laser cutting of alumina [30, 34], by designing appropriate operating conditions [35], by controlled fracture techniques during laser cutting of alumina [36], by investigating 
deformation mechanisms [45], by laser control melting during cutting of straight, rectangular, and triangular geometry into alumina tile [22-25], by using two combined laser sources during surface treatment of alumina-based ceramic [38], and by effective stress management [31-33, 37-44]. The laser processing parameters used by most of these works revealed that the large thermal gradient caused by the localized laser beam generated the thermal stresses, which were generally higher than the fracture and/or yield strength of structural ceramics and are sufficient enough to nucleate micro-cracks that grew during subsequent heating/cooling cycles. Therefore, to improve the quality of laser machining, it is very important to evaluate the magnitude and location of thermal stresses during laser machining and establish tight control on laser machining parameters. However, due to localized nature of laser beam and very short duration of laser-material interaction it is extremely challenging to evaluate thermal stresses via insitu experimental analysis during laser machining of structural ceramics. Furthermore, difficulties associated with preparation of surfaces due to extremely brittle and hard nature of these ceramics it is very difficult, if not impossible, to conduct post-process stress analysis by experimental techniques. In view of this, continuum level (finiteelement) computational modeling approach can be considered as an effective solution.

Previously, the present authors have employed an integrated experimental and computational methodology to investigate the influence of stationary (single [11] or multiple laser pulses [13]) and moving (multiple laser pulses [15]) laser beam during one-, two-, and three-dimensional (1D, 2D, and 3D) laser machining of structural alumina (Fig. 1) (to specifically replicate generic drilling, cutting, and milling operations, respectively) [10,11, 13-17] and their effects on developing surface roughness. This multistep multiphysics computational model incorporated the temperaturedependent material properties and heat transfer and fluid flow boundary conditions to simulate the influence of various physical phenomena (Marangoni convection, recoil pressure, cooling rates, and surface tension) involved during laser machining and their resultant effects on evolving surface roughness, which was also successfully validated for \pm 3 to $5 \%$ error with the experimental observations.

(a) One-dimensional

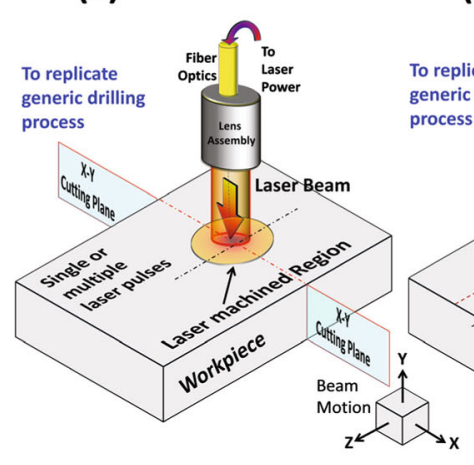

Stationary laser beam and workpiece (b) Two-dimensional

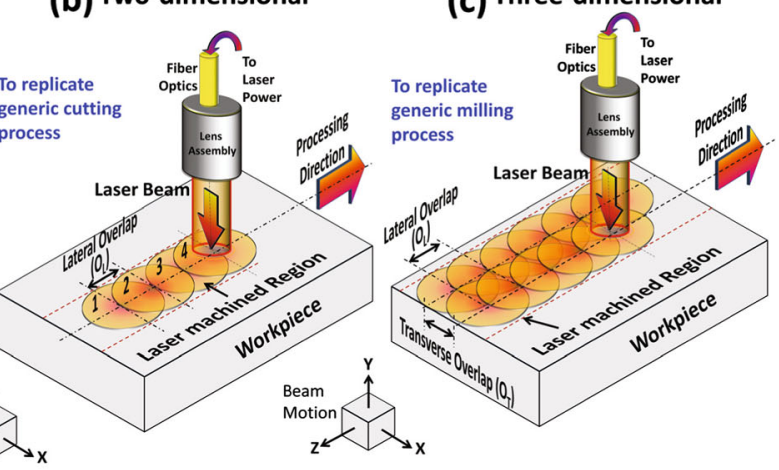

Laser beam moving along Z-axis with lateral overlap $\left(O_{L}\right)$ in Z-axis

\begin{abstract}
Laser beam moving along Z-axis with lateral overlap $\left(\mathrm{O}_{\mathrm{L}}\right)$ in Z-axis and transverse overlap $\left(\mathrm{O}_{\mathrm{T}}\right)$ in $\mathrm{X}$-axis
\end{abstract}

Fig. 1 Classification of pulsed mode $(P M)$ multidimensional laser machining: (a) one-dimensional (single and multiple laser pulses), (b) two-dimensional (multipulse), and (c) three-dimensional (multipulse) 
In extension of these works and as part of the ongoing incremental efforts, an advanced multistep multidimensional multiphysics computational model was developed on commercially available $\mathrm{COMSOL}^{\mathrm{TM}}$ multiphysics finite-element platform. Further, this computational model combined heat transfer, fluid flow, and structural mechanics and incorporated the thermo-mechanic coupling to predict and/or evaluate not only temperature field, fluid flow, and resultant surface topography but also the corresponding thermal stresses during 1-, 2-, and 3D laser machining of structural alumina, which is schematically presented in Fig. 2. Although, the authors are aware that experimentally measured thermal stresses can also be helpful to validate the theoretical prediction, due to several limitations mentioned earlier such as but not limited to localized nature of laser beam-material interaction and difficulties associated with preparation of surface of these brittle and hard structural ceramics; no attempts were made to explore any experimental techniques.

\section{Materials and Methods}

Sample Preparation and Laser Machining

In the present efforts, an alumina slab (porosity $<0.5 \%$ ) with an average equiaxed grain size of $20 \mu \mathrm{m}$ obtained from Advalue Technology Inc., Tucson, AZ was used. The alumina had purity of 99.6 wt. $\%\left(<0.1 \% \mathrm{SiO}_{2},<0.05 \% \mathrm{Fe}_{2} \mathrm{O}_{3}\right.$, and $<0.1 \% \mathrm{R}_{2} \mathrm{O}$ all in wt.\%). JK 701 Lumonics pulsed Nd:YAG (1064 nm wavelength) laser system was

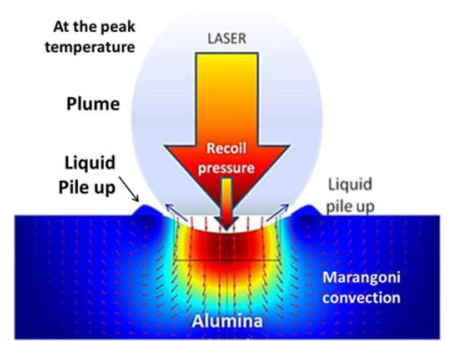

Evolution of physical texture or surface topography

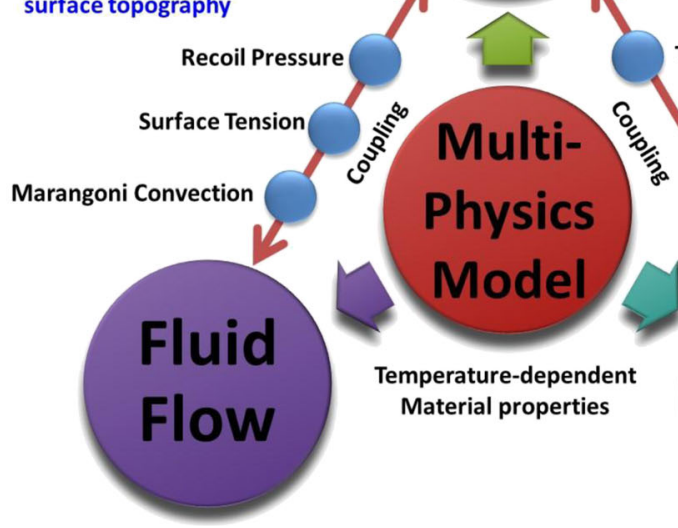

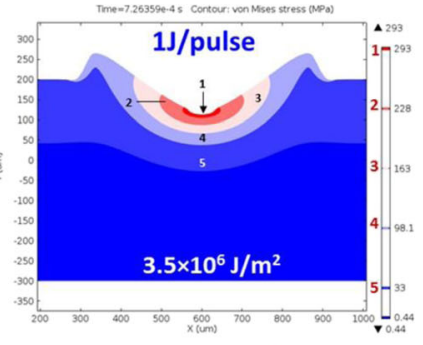

Evolution of thermal stresses (after solidification process)

Temperature

Thermal expansion coefficient

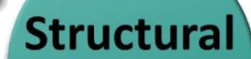
Mechanics

Fig. 2 Schematic of multiphysics multistep computational model adopted in evaluation of thermal stresses 
Table 1 Laser machining parameters employed for laser machining of structural alumina

\begin{tabular}{|c|c|}
\hline Parameter & Value (units) \\
\hline$P_{w}$ & $0.5(\mathrm{~ms})$ \\
\hline$D$ & $0.6(\mathrm{~mm})$ \\
\hline$A$ & 0.25 \\
\hline \multicolumn{2}{|c|}{ One-dimensional laser machining: single laser pulse } \\
\hline$E_{p}$ & $1,1.5,2,2.5,3(\mathrm{~J})$ \\
\hline$f$ & 1 pulse \\
\hline$E_{d}=E_{p} /\left(\frac{\pi}{4} D^{2}\right)$ & $\begin{array}{l}3.5,5.3,7.1,8.8,10.6 \\
\left(\times 10^{6} \mathrm{~J} / \mathrm{m}^{2}\right) \text { respectively }\end{array}$ \\
\hline \multicolumn{2}{|c|}{ One-dimensional laser machining: multiple laser pulses } \\
\hline$E_{p}$ & $1(\mathrm{~J})$ \\
\hline$E_{d}=E_{p} /\left(\frac{\pi}{4} D^{2}\right)$ & $3.5 \times 10^{6} \mathrm{~J} / \mathrm{m}^{2}$ \\
\hline$f$ & $10,20,30,40,50$ pulses \\
\hline$E_{e f f}=\left[E_{p} /\left(\frac{\pi}{4} D^{2}\right)\right] \times f$ & $\begin{array}{l}3.5,7.1,10.6,14.1,17.7 \\
\left(\times 10^{7} \mathrm{~J} / \mathrm{m}^{2}\right) \text { respectively }\end{array}$ \\
\hline \multicolumn{2}{|c|}{ Two-dimensional laser machining: multiple laser pulses } \\
\hline$E_{p}$ & $1(\mathrm{~J})$ \\
\hline$E_{d}=E_{p} /\left(\frac{\pi}{4} D^{2}\right)$ & $3.5 \times 10^{6} \mathrm{~J} / \mathrm{m}^{2}$ \\
\hline$f$ & $17,20,25,34,50,100$ pulses \\
\hline $\operatorname{tg}=1 / f$ & $0.06,0.05,0.04,0.03,0.02,0.01(\mathrm{~s})$ \\
\hline$V$ & $10(\mathrm{~mm} / \mathrm{s})$ \\
\hline$D_{L}=V / f$ & $0.6,0.5,0.4,0.3,0.2,0.1(\mathrm{~mm})$ respectively \\
\hline$O_{L}=\left(\frac{D-D_{L}}{D}\right) \times 100$ & $0,17,33,50,67,83(\%)$ respectively \\
\hline$E_{e f f}=\left[E_{p} /\left(\frac{\pi}{4} D^{2}\right)\right] \times f$ & $\begin{array}{l}6.02,7.08,8.85,12.0,17.7,35.4\left(\times 10^{7} \mathrm{~J} / \mathrm{m}^{2}\right) \\
\quad \text { respectively }\end{array}$ \\
\hline \multicolumn{2}{|c|}{ Three-dimensional laser machining: multiple laser pulses } \\
\hline$D_{T}$ & $0.6,0.5,0.4,0.3,0.2,0.1(\mathrm{~mm})$ respectively \\
\hline$O_{T=}\left(\frac{D-D_{T}}{D}\right) \times 100$ & $0,17,33,50,67,83(\%)$ respectively \\
\hline
\end{tabular}

employed for laser machining of structural alumina. The laser machining parameters used for 1D (single and multiple laser pulses), 2D and 3D laser machining are enumerated in Table 1 and corresponding schematics for multidimensional lasermachined alumina are presented in Fig. 1.

\section{Multistep Multidimensional Multiphysics Computational Model}

During multidimensional laser machining, material experiences various physical phenomena such as phase transition from solid-to-liquid-to-vaporization, material loss during evaporation, and solidification from liquid-to-solid. In addition, material also experiences the transition dependent effects such as thermal expansion during heating, recoil pressure during vaporization, and Marangoni convection and surface tension during solidification. In order to simulate such complex laser machining mechanism, the present model was designed and developed using multistep multiphysics computational modeling approach for multidimensional (1-, 2-, and 3D) laser machining 
process on $\mathrm{COMSOL}^{\mathrm{TM}}$ multiphysics finite-element platform. The present computational model based on the multiphysics approach combined heat transfer, fluid flow, and structural mechanics for thermo-mechanical coupling (temperature and thermal expansion coefficient) to investigate the combinatorial effects of these physical phenomena on evolution of surface topography and thermal stresses as schematically presented in Fig. 2. The selective governing equations and boundary conditions for multiphysics computational model are presented in Table 2 [46-48]. Furthermore, the present computational model incorporated the heat transfer, fluid flow, and structural mechanics boundary conditions (Table 2) corresponding to various physical phenomena (Marangoni convection, surface tension, recoil pressure, and structural deformation) and temperature-dependent material properties (Table 3) (thermal conductivity, heat capacity, elastic modulus, coefficient of thermal expansion, and dynamic viscosity) in order to assess the temperature $(\mathrm{T})$ profile, associated cooling rate, subsequent surface topography, and resultant thermal stresses during 1-, 2-, and 3D laser machining [10-17].

The present model used the thermal stress interface of structural mechanics module to couple solid mechanics interface with a heat transfer interface in such a way that the temperature from the heat transfer interface acts as a thermal load for the solid mechanics interface [49]. To define the linear elastic material properties, the linear elastic material node from the structural mechanics module was specifically assigned to

Table 2 Selective governing equations and boundary conditions for multiphysics computational model

\begin{tabular}{|c|c|c|c|}
\hline Boundary condition & Equation & $\#$ & References \\
\hline $\begin{array}{l}\text { Heat flux, natural } \\
\text { convection cooling } \\
\text { and radiation }\end{array}$ & $\begin{array}{l}\rho c_{p}[\partial T / \partial t]=(\nabla(k(T) \nabla T))+\varphi P_{g} \\
\quad-k(T) \nabla T=-\varphi P_{g}+h\left[T-T_{a}\right]+\varepsilon 1 \sigma 1\left[T^{4}-T_{a}^{4}\right] \\
\text { where, } \varphi=\operatorname{rect} 1\left(\bmod \left(t, \frac{1}{f}\right)\right) \\
\text { Here, } h=10 \mathrm{~W} / \mathrm{m}^{2} . \mathrm{K}, \varepsilon l=0.7, \text { and } \\
T_{a}=298.15 \mathrm{~K}\end{array}$ & (1) and (2) & {$[11-17]$} \\
\hline $\begin{array}{l}\text { Average laser power } \\
\text { density in Gaussian } \\
\text { distribution }\left(\mathrm{W} / \mathrm{m}^{2}\right)\end{array}$ & $P_{g}=A\left[\frac{E_{p}}{P_{w}\left(\frac{\pi}{4} D^{2}\right)}\right] \cdot \exp \left[-\left(\frac{\left(x-x_{r}\right)^{2}}{2 \varnothing^{2}}\right)\right] \cdot \exp \left[-\left(\frac{\left(y-y_{r}\right)^{2}}{2 \varnothing^{2}}\right)\right]$ & (3) & {$[11-17]$} \\
\hline \multirow[t]{3}{*}{ Level set method } & for $\left(T>T_{x}+\Delta T\right)$ & (4) & {$[52,53]$} \\
\hline & $\begin{array}{ll}B=\frac{\left(T-T_{x}+\Delta T\right)}{2 \Delta T} & \text { for }\left(T_{x}-\Delta T\right) \leq T \\
& \leq\left(T_{x}+\Delta T\right) \text { Here } \Delta T=10 \mathrm{~K}\end{array}$ & (5) & \\
\hline & $B=0 \quad$ for $\left(T<T_{x}-\Delta T\right)$ & $(6)$ & \\
\hline Volume force & $\rho g \alpha\left(T-T_{m}\right)$ given by Boussinesq approximation & (7) & {$[52,53]$} \\
\hline Recoil pressure & $\begin{array}{l}P_{r}=\left(P_{g}\right) \frac{1.69}{\sqrt{L_{v}}}\left[\frac{\sqrt{\left(\frac{k \cdot T_{s}}{M_{v} \cdot L_{v}}\right)}}{1+2.2\left(\frac{k \cdot T_{s}}{M_{v} \cdot L_{v}}\right)^{2}}\right] \\
\quad \text { only when } T \geq T_{v}\end{array}$ & (8) & [48] \\
\hline Surface tension & test $(u) *\left[\frac{\partial \gamma \partial T}{\partial T \partial x}\right]$, test $(v) *\left[\frac{\partial \gamma \partial T}{\partial T \partial y}\right]$, test $(w) *\left[\frac{\partial \gamma \partial T}{\partial T \partial z}\right]$ & $\begin{array}{l}(9),(10) \\
\text { and }(11)\end{array}$ & {$[11-17]$} \\
\hline $\begin{array}{l}\text { Total Strain tensor in } \\
\text { terms of displacement } \\
\text { gradient }\end{array}$ & $\begin{array}{l}\nabla u 2=\frac{\partial u 2}{\partial x}, \quad \nabla u 2=\nabla u 2 \approx 1 \\
\therefore \varepsilon=\frac{1}{2}\left[\nabla u 2+(\nabla u 2)^{T}\right]\end{array}$ & (12) & {$[22,49,51]$} \\
\hline Stress tensor & $\begin{array}{l}\sigma=s \\
s=s_{0}+C:\left(\varepsilon-\varepsilon_{0}-\varepsilon_{t h}\right)(\text { Hooke's law) }\end{array}$ & (13) & {$[22,49,51]$} \\
\hline Thermal strain & $\varepsilon_{t h}=\alpha\left(T-T_{r e f}\right)$ Here, $T_{r e f}=298.15 \mathrm{~K}$ & (14) & {$[22,49,51]$} \\
\hline
\end{tabular}


Table 3 Material properties of alumina

\begin{tabular}{|c|c|c|}
\hline Property & Value (units) & References \\
\hline$\rho(T)$ & $3800\left(\mathrm{~kg} / \mathrm{m}^{3}\right)$ & [47] \\
\hline$k(T)$ & $\begin{array}{l}58.868-0.22972 T+2.607 \times 10^{-4} T^{2}-1.3607 \times 10^{-7} T^{3}+2.7092 \times 10^{-11} T^{4} \\
\quad(\mathrm{~W} / \mathrm{m} . \mathrm{K})\end{array}$ & [25] \\
\hline Cp1 (T) & $\begin{aligned} C p & =880+\delta_{m}\left(L_{m}\right)+\left(\frac{L_{m}}{T_{m}}\right) \cdot H^{\prime}\left(\left(T-T_{m}\right), \Delta T\right)+\delta_{v}\left(L_{v}\right) \\
& +\left(\frac{L_{v}}{T_{v}}\right) \cdot H^{\prime}\left(\left(T-T_{v}\right), \Delta T\right)(\mathrm{J} / \mathrm{kg} \cdot \mathrm{K})\end{aligned}$ & {$[11-17]$} \\
\hline$\delta_{m}$, and $\delta_{v}$ & $\frac{\exp \left[-\left(\frac{\left(T-T_{T}\right)^{2}}{\Delta T^{2}}\right)\right]}{\Delta T \sqrt{\pi}}$, and $\frac{\exp \left[-\left(\frac{\left(T-T_{V}\right)^{2}}{\Delta V^{2}}\right)\right]}{\Delta T \sqrt{\pi}}$ & \\
\hline$T_{m}$ & $2324(\mathrm{~K})$ & [47] \\
\hline$T_{v}$ & $3273.15(\mathrm{~K})$ & {$[47]$} \\
\hline$L_{m}$ & $1067.43(\mathrm{~J} / \mathrm{g})$ & {$[47,48]$} \\
\hline$L_{v}$ & $1066.5(\mathrm{~J} / \mathrm{g})$ & {$[47,48]$} \\
\hline$M_{v}$ & $1.693 \mathrm{e}-25(\mathrm{~kg} / \mathrm{atm})$ & {$[47,48]$} \\
\hline$\alpha(T)$ & $\begin{array}{l}\left(-0.23036+7.0045 \times 10^{-4} T+5.681 \times 10^{-8} T^{2}\left(\times 10^{6} 1 / \mathrm{K}\right) \text { valid }\right. \\
\quad \text { for } 298>T<2000 \mathrm{~K}\end{array}$ & {$[25]$} \\
\hline$\partial \gamma / \partial T$ & $-8 \mathrm{e}-5(\mathrm{~N} /(\mathrm{m} . \mathrm{K}))$ & {$[11-17]$} \\
\hline$\gamma(T)$ & $\begin{array}{l}0.64-8.2 \times 10^{-5}\left(T-T_{m}\right) \\
\text { valid for } 2190>T<2500 \mathrm{~K}\end{array}$ & {$[11-17]$} \\
\hline$\mu(T)$ & $3.2 \cdot\left[\exp \left(\frac{43.2 \times 10^{3}}{R T}\right)\right]$ valid for $2190>T<2500 \mathrm{~K}$ & {$[11-17]$} \\
\hline$\sigma 1$ & $5.67 \times 10^{-8}\left(\mathrm{~W} / \mathrm{m}^{2} . \mathrm{K}^{4}\right)$ & [46] \\
\hline$R$ & $8.314(\mathrm{~J} / \mathrm{mol} . \mathrm{K})$ & [46] \\
\hline$g$ & $9.81\left(\mathrm{~m} / \mathrm{s}^{2}\right)$ & [46] \\
\hline$E(T)$ & $407.10-7.3407 \times 10^{2} T(\mathrm{GPa})$ valid for $298>T<2000 \mathrm{~K}$ & [25] \\
\hline$\nu(T)$ & $0.2644+2 \times 10^{-5} T$ valid for $298>T<1300 \mathrm{~K}$ & [25] \\
\hline
\end{tabular}

the linear elastic solid as well as its interface (Table 3). The temperature-dependent elastic modulus and coefficient of thermal expansion were, therefore, assigned to the model to effectively incorporate elastic behavior law (Table 3). In addition, the multiphysics node was added to the present model to incorporate the multiphysics coupling features: (i) thermal expansion and (ii) temperature coupling [49]. Particularly, due the localized nature of laser beam, material experienced higher temperature gradient and associated thermal expansion and strain/deformation during heating and cooling/solidification process. Previously many researchers [22, 50, 51] have shown by their solidification models that the thermal strains which dominate the thermomechanical behavior involved very small strain/deformation during solidification and hence suggested that the strain due to the thermal expansion must be subtracted from the total strain. In the present efforts, the thermal expansion coupling feature introduced by the multiphysics node automatically subtracted thermal expansion induced strain/ deformation from the total strain $[49,51]$. The governing equations related to thermal stress are listed in Table 2 by Eqs. (12-14). The temperature history evaluated from the present multiphysics model was used as input to the thermal stress analysis, which in turn was modeled as von Mises elastic-plastic material with isotropic hardening and a yield stress that changed with temperature [22]. 
The present multiphysics computational model utilized two-step modeling approach to simulate multidimensional (1-, 2-, and 3D) laser machining process for structural alumina. The Step-1 of the computational model (coupled with heat transfer, structural mechanics, and phase change kinetics) was specifically designed and developed to predict the geometry of a crater produced via evaporation losses of the material (Tables 2 and 3). In Step-1, the level-set method [52, 53] (Eqs. (4-6) in Table 2) was employed to trace the interfaces between liquid-solid and vapor-liquid phases so that the elements whose temperature reached above the vaporization temperature were excluded from the geometry. The dimensions of crater (depth and width) play a significant role in predicting the final surface profile and associated thermal stresses. Therefore, in Step-2 of the model the crater geometry predicted from Step-1 was considered as a starting surface profile. The main objective of Step-2 of the computational model (coupled with the heat transfer, fluid flow, structural mechanics, and phase change kinetics) was to predict the combinatorial effects of phase change and associated physical phenomena on the evolving surface topography and thermal stresses (Fig. 2, Table 2, and Table 3).

Nonetheless, the main efforts of the present article being to study the thermal stresses during multidimensional laser machining, the discussion on evolving surface topography is not presented here and can be found in the previous publications [10-17]. It was anticipated that the minimal thermal stress in the vicinity or equal to the fractural strength of the alumina (379 GPa) [54] is sufficient enough to induce/initiate (nucleate) microcracking during laser machining. Thermal stress higher than the fractural stress, although at present the magnitude of such high stress is unknown, is likely to not only induce/ initiate (nucleate) crack but also contribute to its growth/expansion. Also, not only the magnitude of stress but number of pulses and overlap (lateral and transverse) are likely to influence the crack growth and expansion. Furthermore, during multi pulse and the multitrack overlap laser treatment, depending upon the level of thermal stress generated within the region of material treated by the previous laser pulse and previous track, an existing crack is likely to experience growth/expansion in subsequent laser pulses and tracks. Due to the intense stress concentration at the tip of such already existing micro crack it is highly likely to grow/expand at the level of thermal stress (depending upon the magnitude of the stress concentration at the crack tip) less than the theoretical flexural strength of alumina ( $379 \mathrm{GPa}$ ) in the subsequent laser pulses and overlaps. It should be noted that the present analysis only considered the thermal stress of solid phase (just below melting temperature before melting and just below melting temperature after solidification) with the assumptions that the thermal stress field is zero for liquid phase, even though the thermal stresses of all the phases (solid, liquid, and gas) can be numerically predicted [22, 23, 25], the micro cracks are be physically generated and retained only in a solid phase.

The geometry for computational model is presented in the Fig. 3. In order to effectively achieve the savings in computation time and cost, a two-dimensional geometry based on X-Y symmetric cutting plane (Fig. 3a) was designed for onedimensional computational modeling, whereas, a three-dimensional geometry (Fig. 3b) was designed and used for the 2D and 3D computational models. For 1D single pulse laser machining, the dimensions of $A, B, C$, and $D$ are 1200, 500, 200, and $600 \mu \mathrm{m}$, respectively. However, for 1D multipulse laser machining, the dimension of $B$ is $2500 \mu \mathrm{m}$, while dimensions for $A, C$, and $D$ are same as used for 1D single pulse laser machining. Similarly, for 2D and 3D multipulse laser machining, the dimensions of $A, B, C$, and $D$ are 1600, 1200, 200, and $600 \mu \mathrm{m}$, respectively (Fig. 3). 


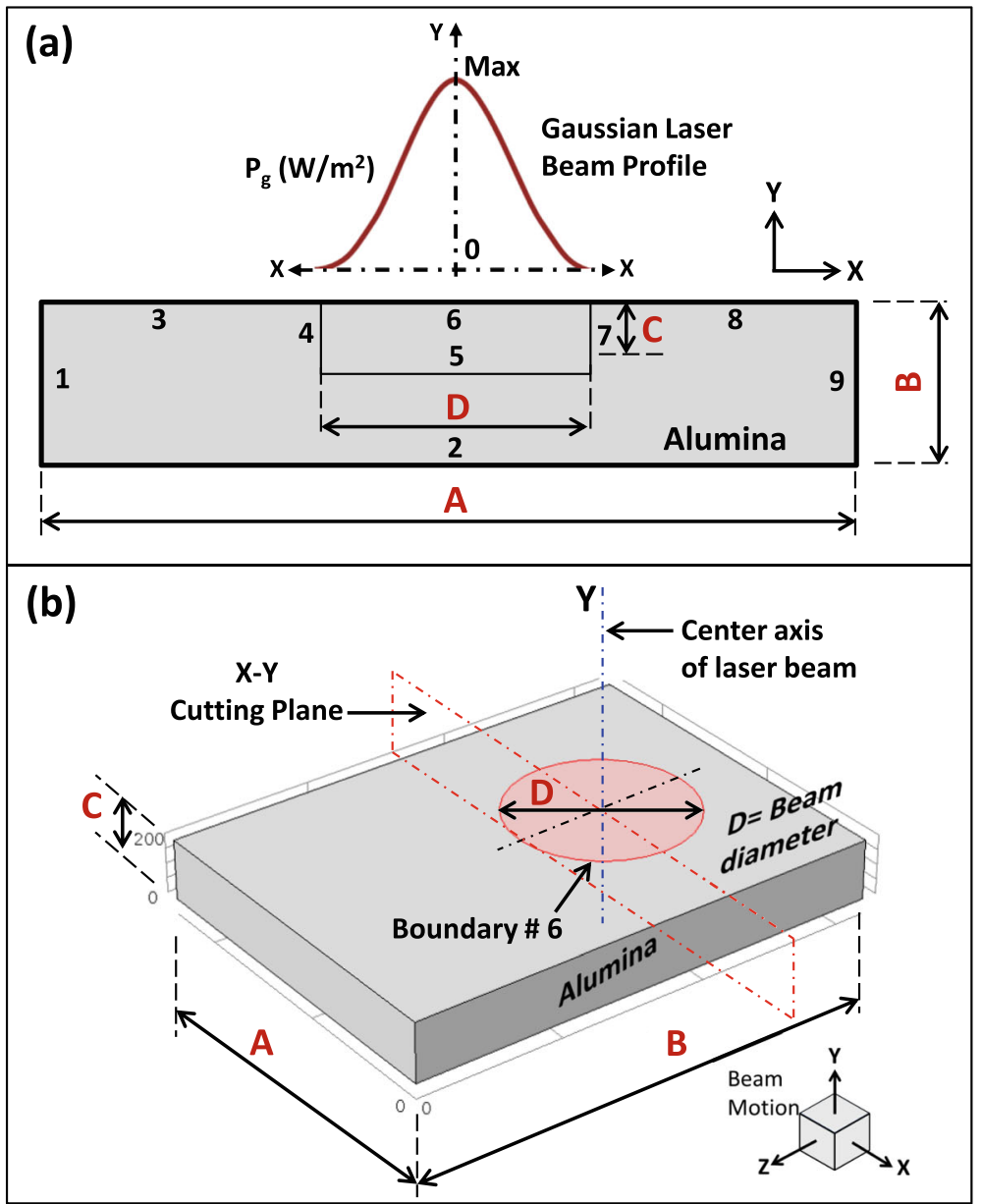

Fig. 3 Geometry for computational model of (a) one-dimensional (single and multiple laser pulse), and (b) two- and three-dimensional multipulse laser machining

Topographical Observations

An environmental scanning electron microscope (ESEM, FEI Quanta 200) was employed to conduct topographical observations of laser machined alumina. The main objective of using ESEM in the present work was to observe and confirm the presence or absence of micro-cracks on the surface of laser machined alumina under various laser machining conditions.

However, in the present efforts, an advanced multiphysics multistep computational model was designed and developed to evaluate thermal stresses during multidimensional (1-, 2-, and 3D) laser machining of structural alumina. The present efforts mainly focused on establishing a link between the computationally predicted thermal stresses and their locations as function of laser processing parameters (energy density, number of pulses, and transverse and lateral overlap) and its correlation with the experimentally observed micro-cracks. Although the discussion/explanation behind the mechanism of 
crack nucleation and growth/expansion during laser machining is important and interest to the authors, it is not a part of the current work. Separate efforts on this aspect are ongoing and will be presented in future publications.

\section{Results and Discussions}

\section{One-Dimensional Laser Machining - Single Laser Pulse}

1D single pulse laser machining was carried out (to replicate generic drilling process, Fig. 1a) by delivering only single laser pulse with stationary laser beam and workpiece to produce shallow hole or develop physical surface texture of shallow depth. Based on the multistep computational model developed for various laser processing conditions during one-dimensional (1D) single pulse laser machining of alumina [11], the transient temperature (T) (Fig. 4a) and thermal stresses (Fig. 4b) as function of time $(t)$ were predicted from the domain probe for various laser energy densities $(3.5,5.3,7.1,8.8$, $10.6 \times 10^{6} \mathrm{~J} / \mathrm{m}^{2}$ ). As described earlier, the present analysis only considered the computationally evaluated thermal stresses of solid phase (before melting and after melting/solidification) $[22,23,25]$, even though the thermal stresses of all the phases (solid, liquid, and gas) can be numerically predicted (Fig. 4b). It should be noted that
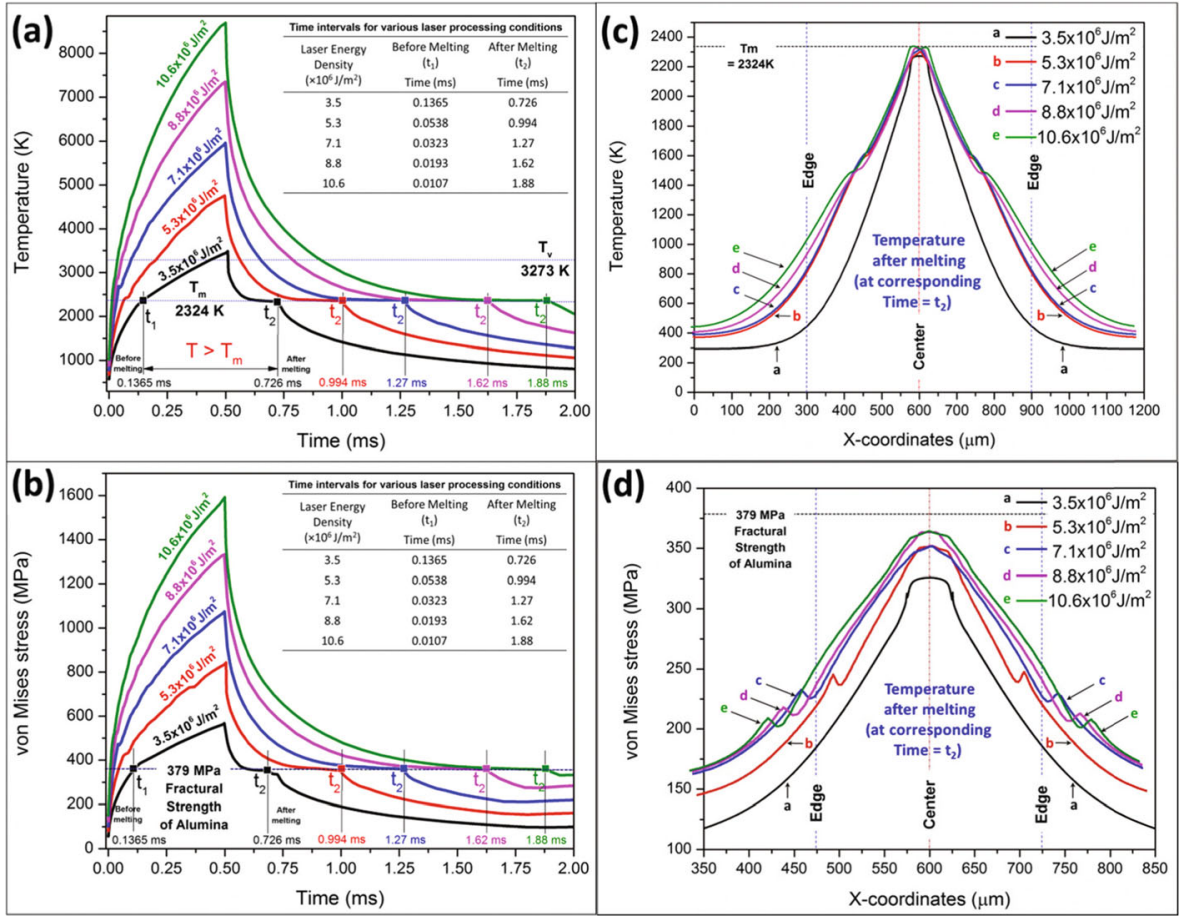

Fig. 4 Computational plots (a) transient temperature and (b) thermal stresses as function of time, (c) temperature and (d) thermal stresses in alumina just below melting temperature during solidification and corresponding time $=t_{2} \mathrm{~ms}$ along boundaries 3,6 , and 8 during one-dimensional (single pulse) laser machining of alumina 
the times $t_{1}$ and $t_{2}$ (Fig. $4 \mathrm{a}$ and $\mathrm{b}$ for all laser processing conditions) are times (in $\mathrm{ms}$ ) corresponding to the times just before melting and below melting during solidification, respectively, and during this time period (between $t_{1}$ and $t_{2}$ ) the temperature $(T)$ is higher than the melting temperature $\left(T_{m}=2324 \mathrm{~K}\right)$ of alumina. In addition, it was also observed that the peak temperature (Fig. 4a) as well as corresponding time period between $t_{1}$ and $t_{2}$, where $T>T_{m}$ increased with an increase in laser energy density.

The spatial temperature (Fig. 4c) and thermal stress (Fig. 4d) distribution just below melting during solidification (corresponding to time $\mathrm{t}_{2}$ ) were also predicted from the boundary probe located on the top surface of the geometry (boundary \#s 3, 6, and 8 , Fig. 3a). Moreover, due to Gaussian distribution of the laser beam, the center of the laser beam supplied higher laser energy density and gradually decreased towards the edges that in turn developed higher temperature at center compared to edges of the laser beam (Fig. 4c). As a result, material experienced preferential heat conduction as well as higher temperature gradient thereby inducing the higher thermal stresses of tensile $(+$ ve) in nature at the center than the edges of the laser beam (Fig. 4d). Furthermore, for 5.3 to $10.6 \times 10^{6} \mathrm{~J} / \mathrm{m}^{2}$ laser energy input (Fig. $4 \mathrm{~d}$ ), a substantial increase in thermal stress around the outer edge region of the laser beam was observed. This is primarily due to the evolution of specific surface topography/profile associated with the piling of solidified material around the lip of machined crater (cavity) during laser machining (Fig. 5) as well as due to the heat conduction (or dissipation) and associated large thermal gradient during single pulse laser machining. However, this effect is negligible for the $3.5 \times 10^{6} \mathrm{~J} / \mathrm{m}^{2}$ laser processing conditions (Fig. 4d) mainly due to the lower energy density $\left(3.5 \times 10^{6} \mathrm{~J} / \mathrm{m}^{2}\right)$ that barely allowed temperature to reach above the vaporization temperature. This resulted in reduced material loss due to evaporation (Fig. 4a), reduced resultant temperature gradient and reduced pile up around the laser interaction zone thereby generating higher magnitude of thermal stresses mainly confined to the center region of the laser beam (Fig. 4d). Nonetheless, it is important to note that the predicted thermal stresses for all laser energy densities $(3.5,5.3,7.1$, $8.8,10.6 \times 10^{6} \mathrm{~J} / \mathrm{m}^{2}$ ) are less than the flexural strength of alumina (379 MPa).

The contour plot illustrating the spatial distribution of thermal stresses just below melting during solidification at time $t_{2}$ and at the room temperature for various laser energy densities $\left(3.5,5.3,7.1,8.8,10.6 \times 10^{6} \mathrm{~J} / \mathrm{m}^{2}\right)$ are presented in Fig. 5a and $\mathrm{b}$ respectively. Based on the predicted temporally and spatially distributed temperature and thermal stress data (Figs. 4 and 5) corresponding to all presently employed 1D single pulse laser machining conditions $(3.5,5.3,7.1$, $8.8,10.6 \times 10^{6} \mathrm{~J} / \mathrm{m}^{2}$ ), it was observed that although the thermal stresses are lower they are close to the fracture strength of alumina (379 MPa). In such situation, it was anticipated that even though the micro-cracks nucleated they did not grow further due to very short duration of laser-material interaction $(0.5 \mathrm{~ms})$ during machining [11]. In view of this, few isolated micro cracks and network of microcracks located in center region of the crater of the laser machined alumina were detected during ESEM observations (Fig. 6).

Fig. 5 Contour plots of thermal stresses during one-dimensional (single pulse) laser machining of alumina (a) just below melting temperature during solidification at time $=t_{2}$ and (b) at room temperature 
(a) at time $=t_{2}$

(b)at room temperature

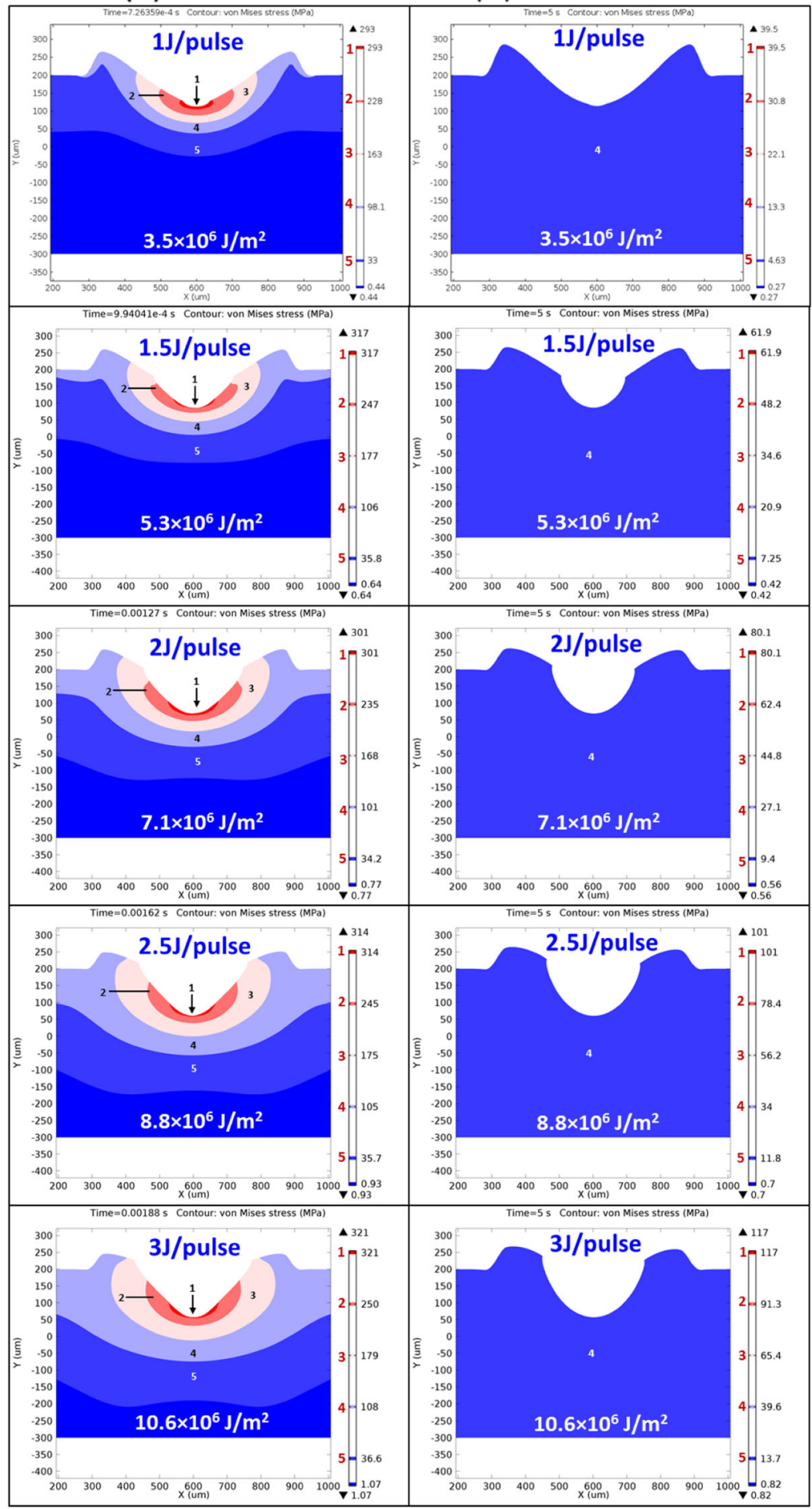




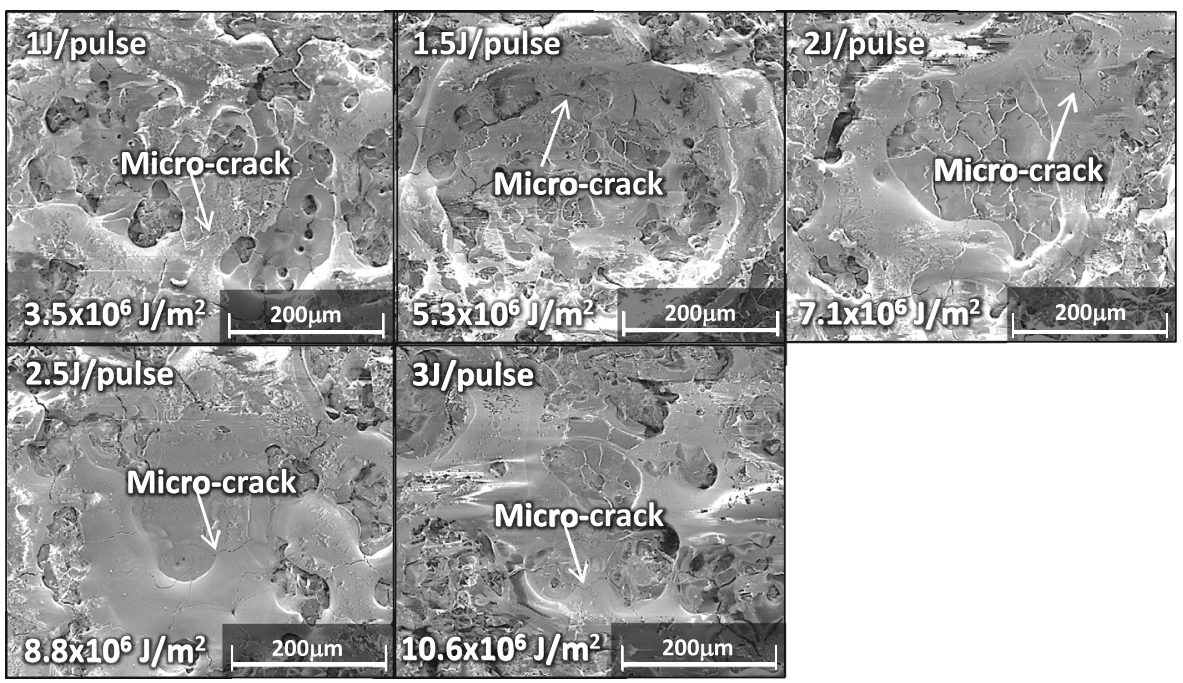

Fig. 6 ESEM photographs of top surface of one-dimensionally (single pulse) laser machined alumina

One-Dimensional Laser Machining - Multiple Laser Pulses

Unlike single pulse 1D laser machining, multipulse 1D laser machining was carried out (to replicate generic drilling process, Fig. 1a) by delivering multiple laser pulses at the same location (with stationary laser beam and workpiece) to create deeper holes at much higher material removal rates. Based on the computational model developed for 1D multipulse laser machining, the thermal stresses were estimated similar to $1 \mathrm{D}$ single pulse laser machining for various laser energy densities $3.5,7.1,10.6,14.1$, and $17.7 \times 10^{7} \mathrm{~J} / \mathrm{m}^{2}$ with $10,20,30$, 40, and 50 laser pulses/second, respectively. It should be noted that the energy per pulse for all 1D multipulse laser machining was $1 \mathrm{~J}$, which was same as the first laser processing condition for 1D single pulse laser machining $\left(3.5 \times 10^{6} \mathrm{~J} /\right.$ $\left.\mathrm{m}^{2}\right)$. However, due to subsequent variation in pulse rates $(10,20,30,40$, and 50 pulses/second) the effective laser energy density varied $(3.5,7.1,10.6,14.1$, and $17.7 \times 10^{7} \mathrm{~J} / \mathrm{m}^{2}$ ) thereby influencing the associated temperature distribution and resultant thermal stresses. Figure 7 presents the contour plot illustrating the spatial distribution of thermal stresses just below melting temperature during solidification after application of the last laser pulse at time $t_{2}$ (Fig. 7a) and at the room temperature (Fig. 7b). The thermal stresses are of tensile (+ve) in nature at both time steps ( $t_{2}$ and room temperature). The thermal stresses at time $t_{2}$ reached near or slightly above the fracture strength of alumina (379 $\left.\mathrm{MPa}\right)$ within the center region of machined crater due to Gaussian beam profile of the laser beam (Fig. 7a). On the contrary, the estimated thermal stresses at room

Fig. 7 Contour plots of thermal stresses during one-dimensional (multiple laser pulses) laser machining of alumina (a) just below melting temperature during solidification corresponding to last laser pulse at time $=t_{2}$ and (b) at room temperature 
(a) at time $=t_{2}$

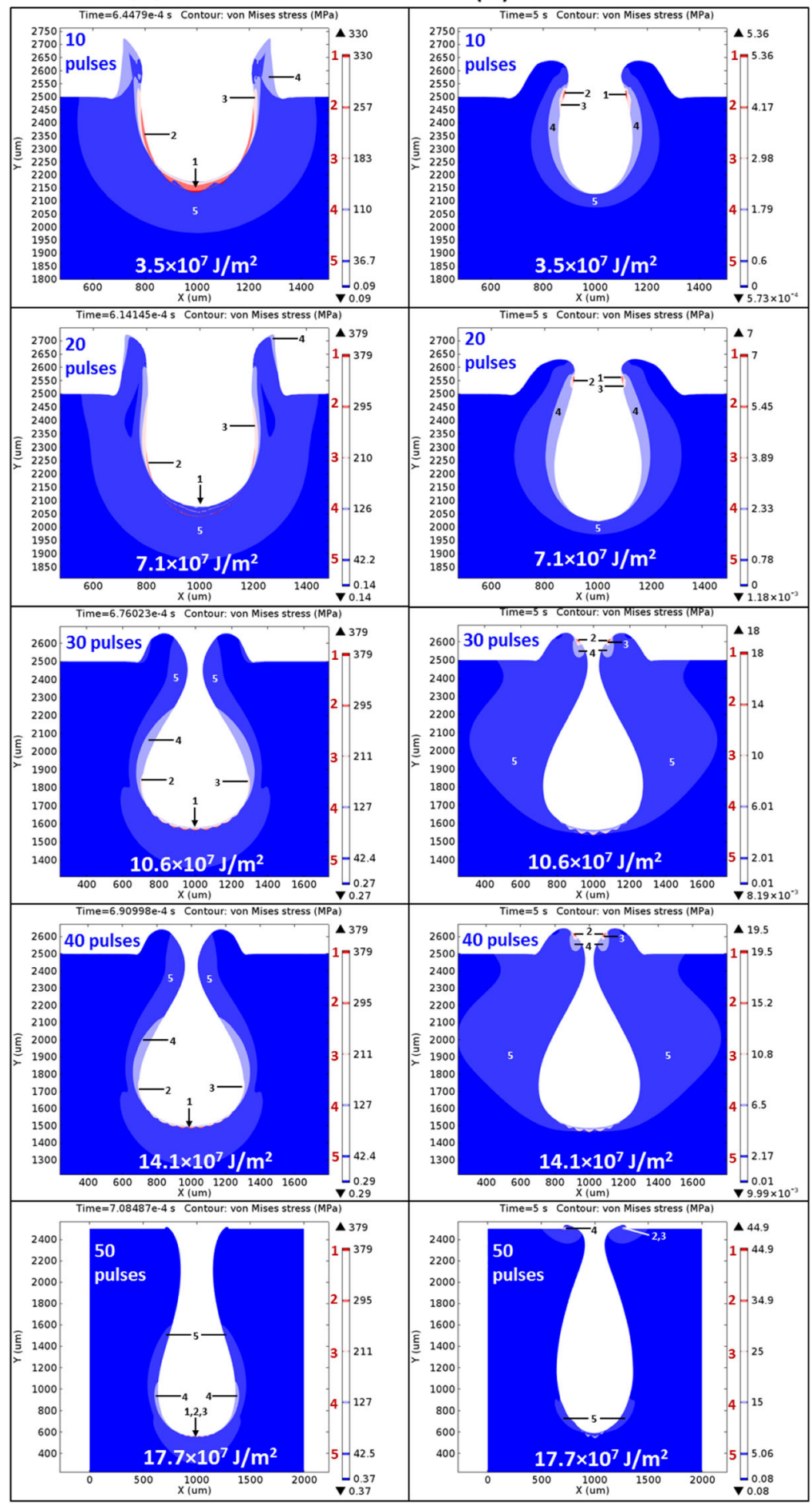


temperature (Fig. 7b) mainly remained substantially below the fracture strength of alumina. This combination of states of stresses at time $=t_{2}$ and room temperature led to nucleation of few isolated cracks without their recognizable growth and expansion (Fig. 8).

\section{Two-Dimensional Laser Machining- Multiple Laser Pulses}

During multipulse 2D laser machining either the laser beam or the workpiece is travelled in relation to the other and simultaneously multiple laser pulses of short pulse width $(0.5 \mathrm{~ms})$ were delivered at defined pulse rate $(f)$ to simulate/replicate generic cutting process (Fig. 1b). As the laser beam was continuously moved along the Z-axis (Fig. 1b), the lateral distance between two laser pulses $\left(D_{L}=\right.$ scanning speed/pulse rate $=V / f)$ and corresponding lateral overlap $\left(O_{L}\right)$, were considerably important for the present process (Fig. 1b). Since, the pulse rate $(f)$ establishes the time duration between two consecutive laser pulses (tg, Table 1), the temperature history and its subsequent effect on the thermal stresses varied. Thus, the appropriate selection of laser processing conditions (scanning speed $(V)$ and pulse rate $(f)$ ) during $2 \mathrm{D}$ laser machining are extremely important to reduce the magnitude of the evolving thermal stresses below the fracture strength of alumina $(379 \mathrm{MPa})$ to possibly produce crack-free components.

It should be noted that the $2 \mathrm{D}$ multipulse laser machining was carried out using $1 \mathrm{~J}$ energy per pulse, which was similar to the first laser processing condition for $1 \mathrm{D}$ single pulse laser machining $\left(3.5 \times 10^{6} \mathrm{~J} / \mathrm{m}^{2}\right)$. However, the combination of scanning speed $(V=10 \mathrm{~mm} / \mathrm{s})$ and pulse rates $(f=17,20,25,34,50$, and 100 laser pulse/second) provided variation in the lateral distance between two laser pulses $\left(D_{L}=0.6,0.5,0.4,0.3,0.2,0.1 \mathrm{~mm}\right)$ and lateral overlap $\left(O_{L}=0,17,33,50,67\right.$, $83 \%)$ and therefore corresponding variation in the effective laser energy density $\left(E_{\text {eff }}=6.02,7.08,8.85,12.0,17.7,35.4 \times 10^{7} \mathrm{~J} / \mathrm{m}^{2}\right.$, Table 1$)$ thereby subsequently

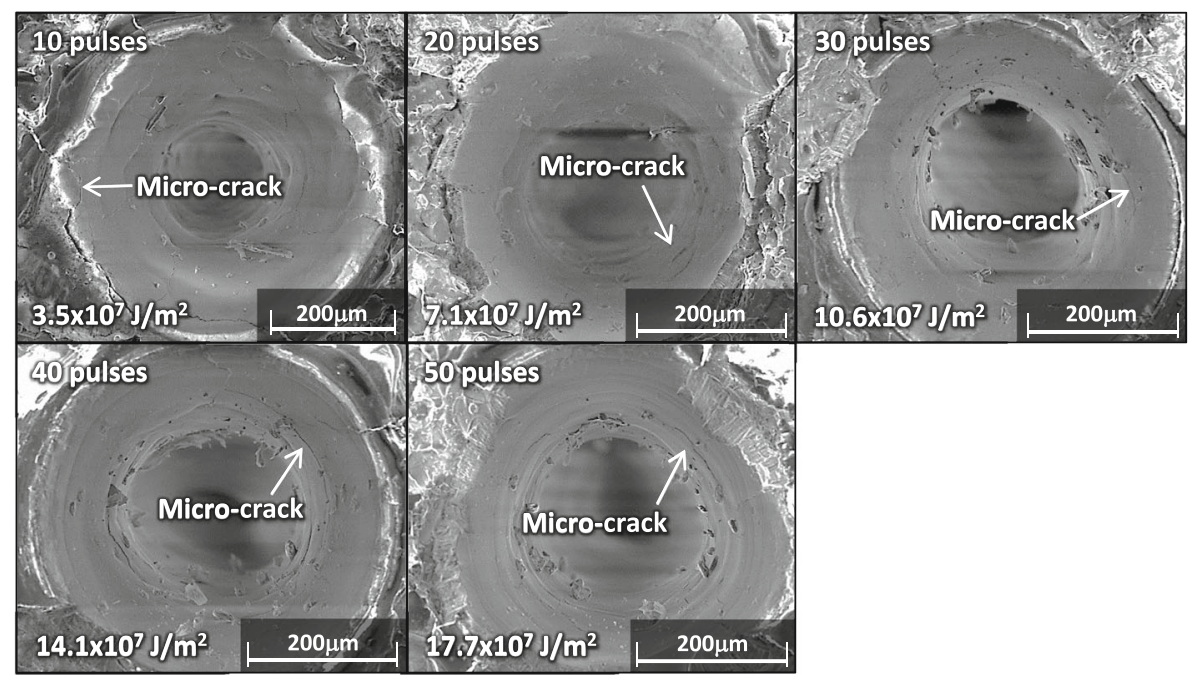

Fig. 8 ESEM photograph of top surface of one-dimensionally (multiple laser pulses) laser machined alumina 
influencing the associated temperature distribution and resultant thermal stresses. Based on the multiphysics computational model developed for 2D laser machining, the temperature history (Fig. 9a) and consequential thermal stresses (Fig. 9b) were predicted for various laser machining conditions $\left(E_{\text {eff }}=6.02,7.08\right.$, $8.85,12.0,17.7,35.4 \times 10^{7} \mathrm{~J} / \mathrm{m}^{2}$, Table 1 ).

Within the range of laser processing conditions employed in the present work, the predicted temperature history did not indicate any significant temperature build up during the subsequent laser pulse delivery [15] (Fig. 9a). The counter plot of the spatial distribution of thermal stresses (Fig. 9b) just below melting temperature during solidification (at time $=t_{2}$ ) after second laser pulse during 2D laser machining of alumina indicated that the thermal stresses are tensile in nature (Fig. 9b). The stresses are highest in the center region of the crater and reached nearly the flexural strength of alumina (379 $\mathrm{MPa}$ ) under all the processing conditions (Fig. 9b). Although, it was anticipated that the micro-cracks may nucleate under such conditions, their further growth/ expansion and evolution into a network depended upon the pulse rate $(f)$ and scanning speed $(V)$ that together controlled the lateral overlap $\left(O_{L}\right)$ between two pulses. As the two consecutive laser pulses were distinctly separated from each other for lateral overlap $\left(O_{L}\right)$ of $0 \%$ for $6.02 \times 10^{7} \mathrm{~J} / \mathrm{m}^{2}$ no network of micro-cracks was observed (Fig. 9b). On the contrary, when the lateral overlap gradually increased $\left(O_{L}\right.$ from 17 to $83 \%$ ) for the lateral distances between two consecutive laser pulses $\left(D_{L}\right)$ from 0.5 to $0.1 \mathrm{~mm}$, the extent of micro-crack network also increased thereby becoming extensive for lateral overlap $\left(O_{L}\right)$ of 67 and $83 \%\left(D_{L}=0.2\right.$ and $\left.0.1 \mathrm{~mm}\right)$ as observed in Fig. 10a and $\mathrm{b}$, respectively.

(a)

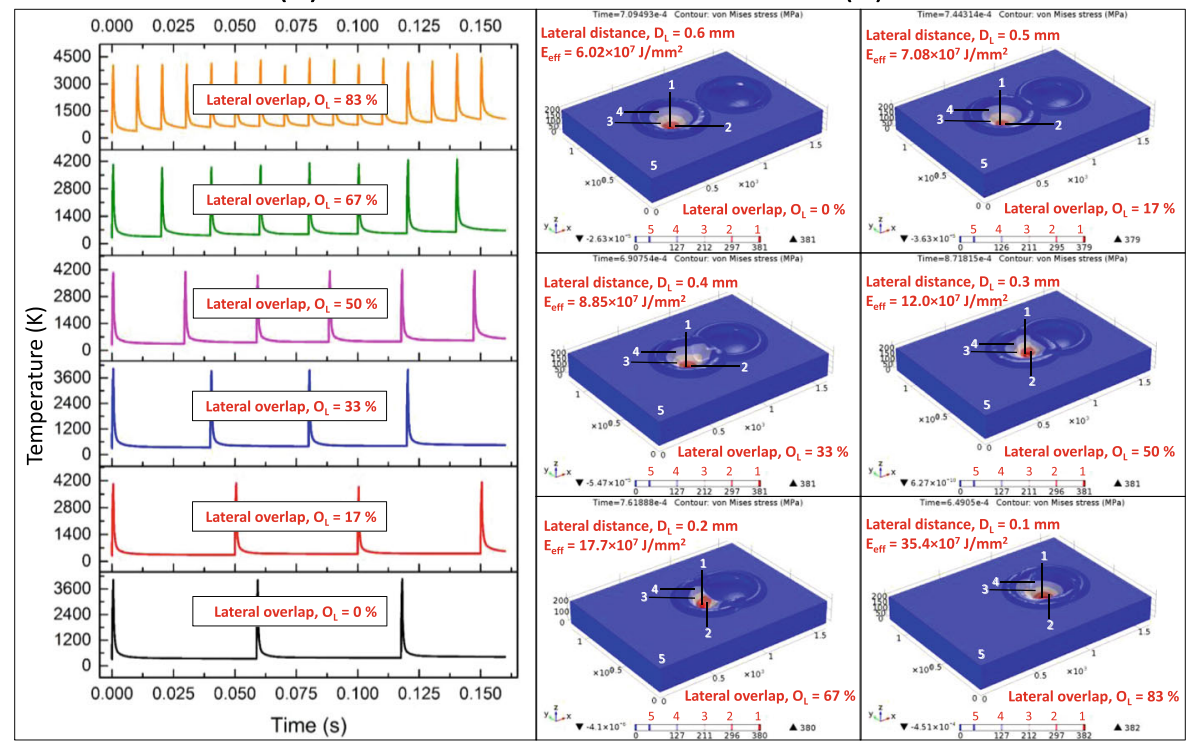

Fig. 9 Computationally predicted (a) temperature history and (b) thermal stresses in alumina just below melting temperature during solidification $\left(\right.$ time $=t_{2}$ ) after second laser pulse during two-dimensional (moving laser, lateral overlap) laser machining of alumina 


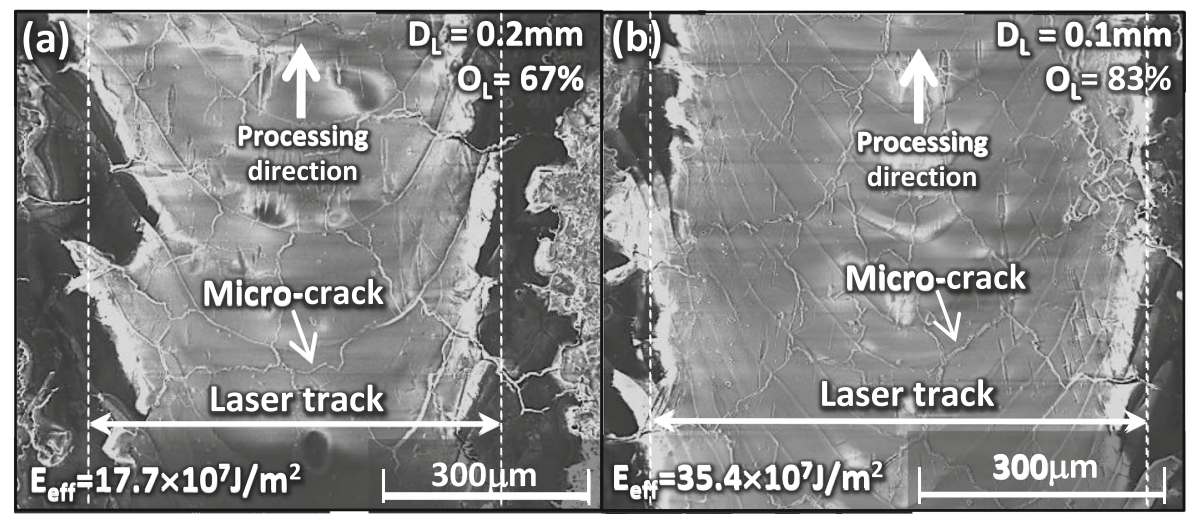

Fig. 10 ESEM photographs of top surface of two-dimensionally laser machined alumina

Three-Dimensional Laser Machining- Multiple Laser Pulses

3D laser machining was carried out to machine large area and complex geometries (Fig. 1c). Due to smaller beam diameter $(\sim 0.6 \mathrm{~mm}), 3 \mathrm{D}$ laser machining involved laying of successive laser tracks with the combination of lateral overlap (overlap between two consecutive laser pulses, $O_{L}$ ) and transverse overlap (overlap between two laser tracks, $O_{T}$ ) to cover larger area or volume (Fig. 1c). Thus, unlike 2D laser machining, the 3D laser machining was carried out by using both lateral $\left(O_{L}\right)$ and transverse $\left(O_{T}\right)$ overlaps in various scanning configurations [16]. In view of this, appropriate multistep multiphysics computational model (moving laser beam, multiple laser pulses) was designed and developed to predict the temperature history and corresponding thermal stresses for various laser machining conditions $\left(E_{\text {eff }}=6.02\right.$, $7.08,8.85,12.0,17.7,35.4 \times 10^{7} \mathrm{~J} / \mathrm{m}^{2}$, corresponding to $D_{L}-D_{T}=0.6-0.6,0.5-0.5$, $0.4-0.4,0.3-0.3,0.2-0.2,0.1-0.1 \mathrm{~mm}$ and $O_{L}-O_{T}=0-0 \%, 17-17 \%, 33-33 \%, 50$ $50 \%, 67-67 \%, 83-83 \%$, respectively, Table 1). Similar to 2D laser machining, every pulse in all sets of the processing conditions of 3D laser machining employed $1 \mathrm{~J}$ laser energy per pulse $\left(3.5 \times 10^{6} \mathrm{~J} / \mathrm{m}^{2}\right.$, Table 1$)$ and no temperature build up was experienced (Fig. 9a) [16]. Thus, although the thermal history of the individual pulse and individual laser track remained same, the combination of delivery of lateral $\left(O_{L}\right)$ and transverse $\left(O_{T}\right)$ laser tracks may affect the thermal stresses and their effect on the pre-existing micro-cracks and nucleation and growth of new micro-cracks.

Based on the present multistep multiphysics computational model for 3D laser machining, the spatial distribution of thermal stresses were computed for $3.5 \times$ $10^{6} \mathrm{~J} / \mathrm{m}^{2}$ laser energy density along the top surface (Fig. 11a) in X-Z cutting plane (Fig. 3b) and around the center axis of laser beam (Fig. 11b) in X-Y cutting plane (Fig. 3b) just below melting temperature during solidification (time $=t_{2}$ ) at the end of the last laser pulse during 3D laser machining of alumina (Fig. 11). As a consequence, just below melting temperature during solidification (time $=t_{2}$ ) the corresponding thermal stresses were tensile in nature, (+ve) in both spatial and depth distributions (Fig. 11). Due to the Gaussian laser beam profile the stresses were highest in the center region and dropped towards outer region (Fig. 11a). 

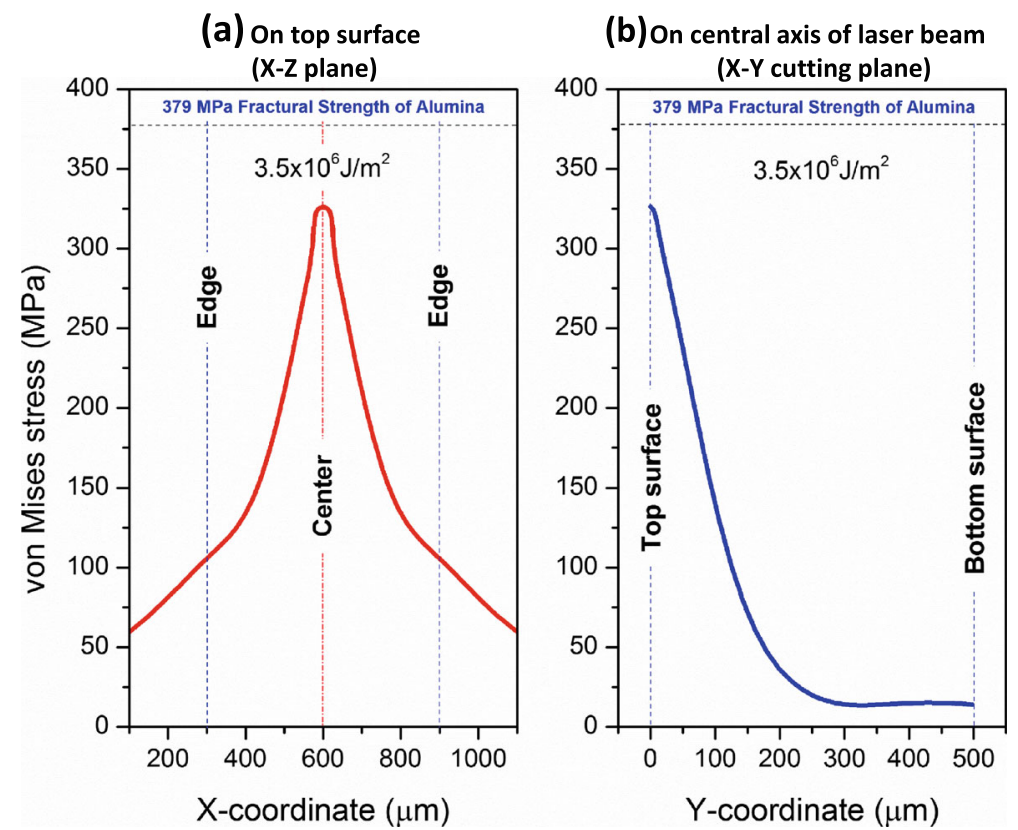

Fig. 11 Predicted thermal stresses (a) on the top surface and (b) just below melting temperature during solidification ( $\left(\right.$ ime $=t_{2}$ ) at the end of the last laser pulse during three-dimensional laser machining of alumina

Furthermore, the depth profile (Fig. 11b) indicated that the stresses were high on the surface and dropped off substantially through the depth of $\sim 200 \mu \mathrm{m}$. Thus, both surface and depth profiles (Fig. 11) indicated that the stresses on the surface evolved closed to the flexural strength of alumina (379 MPa) with the possibilities for nucleation and generation of micro-cracks. Accordingly, ESEM observations revealed the presence of few isolated cracks on the surfaces of samples processed under all six laser processing conditions employed during 3D laser machining in the present efforts (Fig. 12).

Although, laser processing conditions (laser energy densities) within the individual laser track of all six processing conditions of both 2D and 3D machining were same (Table 1), unlike 2D machining (Fig. 10), ESEM observations indicated the absence of network of micro-cracks on the surfaces of all 3D machined samples (Fig. 12). Such pronounced difference was expected due to various overlapped laser tracks $\left(O_{T}\right)$ produced by transverse shifts $\left(D_{T}\right)$ in subsequent laser tracks required during $3 \mathrm{D}$ machining. The various overlaps produced under six different laser processing conditions $\left(O_{L}-O_{T}=0-0 \%, 17-17 \%, 33-33 \%, 50-50 \%, 67-67 \%, 83-83 \%\right.$, respectively, Table 1) employed in the present work likely to have melted/sealed the (network of) micro-cracks produced during previous laser tracks thereby generating the machined surfaces with few isolated micro-cracks (Fig. 12).

Theoretically the micro-cracks can be nucleated when the thermal stress reaches near or equal to the flexural strength limit of structural alumina (379 MPa). However, based on the observed results it was found that the number of laser pulses in $1 \mathrm{D}$ and $2 \mathrm{D}$ laser machining, the presence of lateral overlap $\left(O_{L}\right)$ during 2D and 3D laser machining, and also transverse overlap $\left(O_{T}\right)$ during $3 \mathrm{D}$ laser machining significantly influenced the 


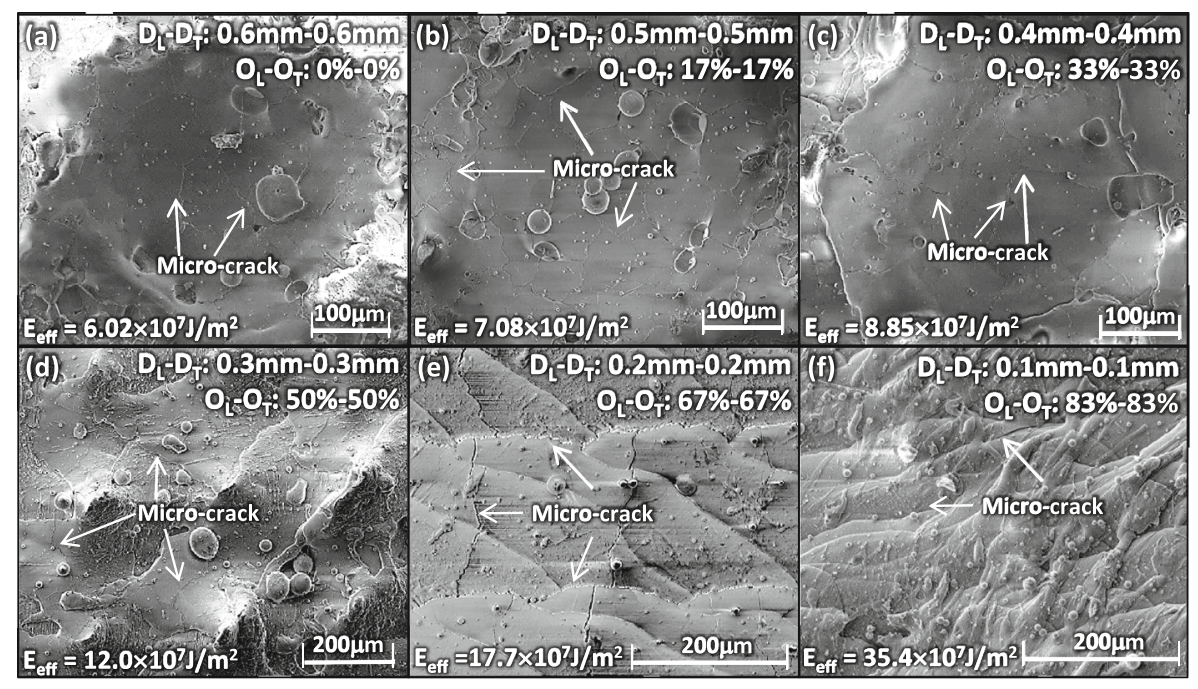

Fig. 12 ESEM photographs of top surface of three-dimensionally laser machined alumina

amount and nature of micro-cracks due to the thermal expansion difference between the laser material interaction region and surrounding substrate material. Depending upon the level of thermal stress generated within the region of material treated by the previous laser pulse (during multi pulse treatment) and the laser track overlap (lateral and transverse), it is likely to experience initiation (nucleation) and/or growth/expansion of micro crack(s). Furthermore, due to the intense stress concentration at the tip of such already existing micro crack is highly likely to grow/expand at the level of thermal stress (depending upon the magnitude of the stress concentration at the crack tip) less than the theoretical flexural strength of alumina (379 GPa) in the subsequent laser pulses and overlaps. The extent of micro crack and generation of micro crack network depends upon the magnitude of laser parameters (pulse frequency, pulse energy, and magnitude of overlap).

\section{Conclusion}

An advanced multiphysics multistep computational model was designed and developed to evaluate thermal stresses during multidimensional (1-, 2-, and 3D) laser machining of structural alumina. The present multistep model incorporated heat transfer, fluid flow, structural mechanics boundary conditions, multiphysics (thermo-mechanical) coupling, and temperature-dependent materials properties to effectively simulate multidimensional (1-, 2-, 3D) laser machining conditions. The results of this investigation indicated that the theoretically evaluated thermal stresses (in spatial and depth distribution) for multidimensional (1-, 2-, and 3D) laser machining were tensile (+ve) in nature and predominately high on the surface and in the center region of laser beam reaching nearly the flexural strength of structural alumina (379 MPa). Such state of stresses led to nucleation of few isolated micro-cracks during multidimensional (1-, 2-, and 3D) laser machining. However, the number of laser pulses in $1 \mathrm{D}$ and 2D laser 
machining, the presence of lateral overlap $\left(O_{L}\right)$ during 2D and 3D laser machining, and also transverse overlap $\left(O_{T}\right)$ during 3D laser machining significantly influenced the amount and nature of micro-cracks due to the thermal expansion difference between the laser interaction region and surrounding substrate material. Furthermore, the present research approach/methodology indicated tremendous promise in adopting laser based machining to efficiently and effectively produce defect-free components at high material removal rates and desired surface roughness from difficult-to-machine materials.

Acknowledgments The authors, NBD and HDV would like to acknowledge the financial support from the National Science Foundation (NSF-CMMI 1010494). The authors would also like to recognize the Center for Advanced Research Technology (CART) at the University of North Texas for providing the characterization facilities.

\section{References}

1. Richerson, D.: Modern ceramic engineering: properties, processing, and use in design. (2005)

2. Tian, Y., Shin, Y.C.: Thermal modeling for laser-assisted machining of silicon nitride ceramics with complex features. J. Manuf. Sci. Eng. 128, 425-434 (2006)

3. Firestone, R.,Vesely Jr, E.: High power laser beam machining of structural ceramics. 215-227 (1988)

4. Dahotre, N.B.,Samant, A.N.: Laser machining of advanced materials. (2011)

5. Dubey, A.K., Yadava, V.: Laser beam machining — a review. Int. J. Mach. Tools Manuf. 48, 609-628 (2008)

6. Samant, A.N., Dahotre, N.B.: Laser machining of structural ceramics - a review. J. Eur. Ceram. Soc. 29, 969-993 (2009)

7. Islam, M., Campbell, G.: Laser machining of ceramics: a review. Mater. Manuf. Process. 8, 611-630 (1993)

8. Samant, A.N.: Laser Machining of Structural Ceramics: Computational and Experimental Analysis. PhD Dissertation, University of Tennessee (2009)

9. Tuersley, I., Jawaid, A., Pashby, I.: Review: various methods of machining advanced ceramic materials. J. Mater. Process. Technol. 42, 377-390 (1994)

10. Vora, H.D., Dahotre, N.B.: Laser machining of structural ceramics. Am. Ceram. Soc. Bull. 92, 29-30 (2013)

11. Vora, H.D., Santhanakrishnan, S., Harimkar, S.P., Boetcher, S.K.S., Dahotre, N.B.: Evolution of surface topography in one-dimensional laser machining of structural alumina. J. Eur. Ceram. Soc. 32, 4205-4218 (2012)

12. Vora, H.,Paital, S.,Harimkar, S.,Boetcher, S.Dahotre, N.: Experimental and Numerical Approach for Surface Finish during Laser Machining of Alumina. Materials Science and Technology Conference and Exhibition 2011, Columbus, Ohio, USA, 1493-1500 (2012)

13. Vora, H.D., Santhanakrishnan, S., Harimkar, S.P., Boetcher, S.K.S., Dahotre, N.B.: One-dimensional multipulse laser machining of structural alumina: evolution of surface topography. Int. J. Adv. Manuf. Technol. 68, 69-83 (2013)

14. Vora, H.D., Dahotre, N.B., Laser Machining of Structural Ceramics: An Integrated Experimental and Numerical Approach for Surface Finish. UNT Digital Library, http://digital.library.unt.edu/ark:/67531/ metadc152429/. (2013)

15. Vora, H.D.,Dahotre, N.B.: Laser Machining of Structural Alumina: Influence of Moving Laser Beam on the Evolution of Surface Topography. Int. J.Appl. Ceram. Technol. 1-14 (2014)

16. Vora, H.D.,Dahotre, N.B.: Integrated Experimental and Computational Approach to Control Physical Texture during Three-Dimensional Laser Machining of Structural Alumina. Manuscript submitted to Journal of Manufacturing Processes (July 17, 2014) (May 2014)

17. Vora, H.D.: Integrated Computational and Experimental Approach to Control Physical Texture during Laser Machining of Structural Ceramics. PhD Dissertation (2014)

18. Moncayo, M.A., Santhanakrishnan, S., Vora, H.D., Paital, S.R., Dahotre, N.B.: Laser surface modification of alumina: integrated computational and experimental analysis. Ceram. Int. 39, 6207-6213 (2013) 
19. Moncayo, M.A., Santhanakrishnan, S., Vora, H.D., Dahotre, N.B.: Computational modeling and experimental based parametric study of multi-track laser processing on alumina. Opt. Laser Technol. 48, 570579 (2013)

20. Lei, S., Shin, Y.C., Incropera, F.P.: Experimental investigation of thermo-mechanical characteristics in laser-assisted machining of silicon nitride ceramics. J. Manuf. Sci. Eng. 123, 639-646 (2001)

21. Rozzi, J.C., Pfefferkorn, F.E., Shin, Y.C., Incropera, F.P.: Experimental evaluation of the laser assisted machining of silicon nitride ceramics. J. Manuf. Sci. Eng. 122, 666-670 (2000)

22. Yilbas, B.S., Akhtar, S., Karatas, C.: Laser straight cutting of alumina tiles: thermal stress analysis. Int. J. Adv. Manuf. Technol. 58, 1019-1030 (2012)

23. Yilbas, B., Akhtar, S., Karatas, C.: Laser cutting of rectangular geometry into alumina tiles. Opt. Lasers Eng. 55, 35-43 (2014)

24. Yilbas, B.S., Akhtar, S.S., Karatas, C.: Laser cutting of triangular geometry into alumina tiles: morphological changes and thermal stress analysis. Mach. Sci. Technol. 18, $424-447$ (2014)

25. Yilbas, B., Karatas, C., Arif, A.A., Aleem, B.: Laser control melting of alumina surfaces and thermal stress analysis. Opt. Laser Technol. 43, 858-865 (2011)

26. Rebro, P.A., Shin, Y.C., Incropera, F.P.: Laser-assisted machining of reaction sintered mullite ceramics. J. Manuf. Sci. Eng. 124, 875-885 (2002)

27. Tian, Y., Shin, Y.C.: Multiscale finite element modeling of silicon nitride ceramics undergoing laserassisted machining. J. Manuf. Sci. Eng. 129, 287-295 (2007)

28. Rebro, P.A., Pfefferkorn, F., Shin, Y., Incropera, F.: Comparative assessment of laser-assisted machining for various ceramics. Trans N. Am. Manuf. Res. Inst. Soc Manufact. Eng. (NAMRI/SME). 30, 153-160 (2002)

29. Pfefferkorn, F.E., Shin, Y.C., Tian, Y., Incropera, F.P.: Laser-assisted machining of magnesia-partiallystabilized zirconia. J. Manuf. Sci. Eng. 126, 42-51 (2004)

30. Akarapu, R., Li, B., Segall, A.: A thermal stress and failure model for laser cutting and forming operations. J. Fail. Anal. Prev. 4, 51-62 (2004)

31. Hasselman, D.: Thermal stress resistance of engineering ceramics. Mater. Sci. Eng. 71, 251-264 (1985)

32. Kingery, W.D.: Factors affecting thermal stress resistance of ceramic materials. J. Am. Ceram. Soc. 38, 315 (1955)

33. Tönshoff, H., Emmelmann, C.: Laser cutting of advanced ceramics. CIRP Ann-Manuf.Technol. 38, 219222 (1989)

34. Akarapu, R., Segall, A.E.: Numerical simulations of an active-stressing technique for delaying fracture during cutting of alumina. J. Manuf. Sci. Eng. 128, 921-927 (2006)

35. Rebro, P.A., Shin, Y.C., Incropera, F.P.: Design of operating conditions for crackfree laser-assisted machining of mullite. Int. J. Mach. Tools Manuf. 44, 677-694 (2004)

36. Tsai, C., Chen, C.: Formation of the breaking surface of alumina in laser cutting with a controlled fracture technique. Proc. Inst. Mech. Eng. Pt. B: J. Eng. Manuf. 217, 489-497 (2003)

37. Gross, T., Hening, S., Watt, D.: Crack formation during laser cutting of silicon. J. Appl. Phys. 69, 983-989 (1991)

38. Triantafyllidis, D., Li, L., Stott, F.: Surface treatment of alumina-based ceramics using combined laser sources. Appl. Surf. Sci. 186, 140-144 (2002)

39. Modest, M.F.: Transient elastic and viscoelastic thermal stresses during laser drilling of ceramics. TransAm. Soc. Mech. Eng. J Heat Tran. 120, 892-898 (1998)

40. Modest, M.F., Mallison, T.M.: Transient elastic thermal stress development during laser scribing of ceramics. J. Heat Transf. 123, 171-177 (2000)

41. Molian, R., Shrotriya, P., Molian, P.: Thermal stress fracture mode of CO2 laser cutting of aluminum nitride. Int. J. Adv. Manuf. Technol. 39, 725-733 (2008)

42. Sumi, N., Hetnarski, R.B., Noda, N.: Transient thermal stresses due to a local source of heat moving over the surface of an infinite elastic slab. J. Therm. Stresses 10, 83-96 (1987)

43. Xu, Z.M., Hong, Z.H.: Experimental investigation on laser milling of Al2O3 ceramic. Appl. Mech. Mater. 457, 160-163 (2014)

44. Zhang, X.,Chen, G.,An, W.,Deng, Z.Zhou, Z.: Experimental investigations of machining characteristics of laser-induced thermal cracking in alumina ceramic wet grinding. Int. J. Adv. Manuf. Technol. 1-7 (2014)

45. Lei, S., Shin, Y.C., Incropera, F.P.: Deformation mechanisms and constitutive modeling for silicon nitride undergoing laser-assisted machining. Int. J. Mach. Tools Manuf. 40, 2213-2233 (2000)

46. Kannatey-Asibu, E.: Principles of laser materials processing. (2009)

47. Gitzen, W.H.: Alumina as a ceramic material. (1970)

48. Harimkar, S.P., Samant, A.N., Dahotre, N.B.: Temporally evolved recoil pressure driven melt infiltration during laser surface modifications of porous alumina ceramic. J. Appl. Phys. 101, 054911-054911-7 (2007) 
49. Structural Mechanics Module: User's Guide. COMSOL Multiphysics Documentation. V 4.4 (2014)

50. Risso, J.M., Huespe, A.E., Cardona, A.: Thermal stress evaluation in the steel continuous casting process. Int. J. Numer. Methods Eng. 65, 1355-1377 (2006)

51. Roger, F.,Traidia, A.: Modeling Residual Stresses in Arc Welding. Proceedings of the COMSOL Conference (2010)

52. Sussman, M., Smereka, P., Osher, S.: A level set approach for computing solutions to incompressible twophase flow. J. Comput. Phys. 114, 146-159 (1994)

53. COMSOL: Continuous casting model. COMSOL Multiphysics model library. V 4.2a (2011)

54. http://www.advaluetech.com/alumina99_technical_info.html. (2013) 